\title{
PERSONALIZED LEARNING IN MATH, THROW PROBLEM-SOLVING, AND THE USE OF ICT
}

\author{
Diana Starja ${ }^{1}$, Nikolina Nikolova ${ }^{1}, \&$ Bederiana Shyti ${ }^{2}$ \\ ${ }^{I}$ University of Sofia "St. Kliment Ohridski" (Bulgaria) \\ ${ }^{2}$ Aleksandër Xhuvani University of Elbasan (Albania)
}

\begin{abstract}
The challenge of learning math for the 21 st century is personalized learning. Personalized learning in math gives everyone the chance to touch the greatness of mathematics.

Personalizing math learning means designing, developing, and applying teaching strategies and techniques while taking into account everyone's skills and intelligence. Personalized learning in mathematics is a necessity, to create opportunities according to the abilities to achieve the ultimate goal, which is the preparation of the capable citizens of tomorrow. Since problem-solving leads the list of skills and competencies that need to be achieved through math learning, developing math learning through problem-solving doubles the importance of learning math. And, if we further add to this mixing with fully defined relationships: personalized learning + problem-solving, we add another element that should characterize today's learning, which is the use of technology, we can prepare generations that not only can learn math but also produce math being the forerunners of technological change to make their implementation in every area of life.

In this article, we will see how we can achieve personalized learning through problem-solving in mathematics in Lower Secondary Education (AMU, in Albanian) and the role that ICT plays in achieving the highest possible results.
\end{abstract}

Keywords: Personalized learning in math, problem-solving, ICT, gifted and talented, success in math.

\section{Introduction}

The education system around the world has on its shoulders the weight of the positive change of the world as a whole, as well as the function of the regulator of all other systems, on which states operate. In these conditions, it is the essential task of the entire education system to design and be the forerunner of all the changes that take place in all areas of life. Education systems need to prepare generations of students, who need to be practical and have a clear mind to face challenges and move forward.

At the same time, by mastering these two qualities, the students immediately adapt and successfully cope with this technological boom that has been served to the world. The concept of education as a whole is very broad, but the field of mathematics is the pillar of education as a whole.

For this reason, orientation policies regarding teaching and learning mathematics around the world have clearly and foresightfully defined future teaching and learning practices, based on clear ideas and principles to make them as resistant to change as possible. But while mathematics is the pillar of education as a whole, problem-solving is the pillar of mathematical learning. On the other hand, technology plays the role of strengthening teaching practices, by creating conditions to enable this new form of learning and to promote and activate these transformative approaches to the future-oriented learning process.

\section{Personalized learning}

\subsection{What is personalized learning?}

Personalized learning has long been a challenge for teachers, who are passionate about teaching. It requires differentiated treatment for differentiated needs, according to differentiated skills. Personalized learning means the differentiated provision to meet differentiated needs. (Leadbeater, 2005). The teacher is now no longer in the center of attention, he is the support of his students, who learn through a very wide range of great modalities. In this way, he should guide the critical thinking and creative abilities of his students by encouraging them to conclude and by giving them the satisfaction of something they discover for the first time. 


\subsection{Personalized learning in mathematics}

21st Century education has 7 key features that make it different from a 20th Century approach. These are (1) Personalized learning. (2) Equity, diversity, and inclusivity. (3) Learning through doing. (4) Changed roles of the teacher. (5) Community relations. (6) Technology. (7) Teacher professionalization. (Bolstad, et al., 2012).

Children of a certain age group each have their mental potential, they are very complex and have developed their senses in different ways. The focus of all math teachers should be on adapting the teaching style, depending on the more developed skills that his students have. From this point of view, considering the theory on the learning modalities of Chris Drew (Drew, Re-examining cognitive tools: new developments, new perspectives, and new opportunities for educational technology research, 2019), which classifies them into 4 major groups, such as visual, auditory, kinesthetic, and tactile, and given the fact that students in a class have different inclinations and diverse abilities, math teachers should use a variety of modalities to suit the needs of students. Mathematically we would express personalized learning with this identity (Figure 1):

Figure 1. Personalized learning model.

One way to personalize learning math is by differentiating the difficulty of the content, unlike older teaching models where all students learn the same content at the same time. Personalized learning is related to the ambitious teaching of mathematics and as such it is very well suited to talented students.

The average level of the classroom loses talented students. But as we search for a wide range of modalities, techniques, and strategies, for personalized learning we remember that problem-solving will always be there, to enable us to achieve the highest possible learning outcomes. On the other hand, the implementation of ICT in teaching increases the opportunities that we can offer students for better quality learning in mathematics. Technology is not just a tool. It can give learners a voice that they may not have had before (Couros, 2011).

\subsection{Personalized learning in math through problem-solving and ICT}

Developing math through problem-solving means encouraging students to reason rather than memorize certain mathematical template facts and knowledge. Problem-solving is not only a goal of learning math but also a key tool for doing so (National Council of Teachers of Mathematics (NCTM), 2000).

On the other hand, moderating the role of the teacher not to provide ready-made mathematics, but to teach students to produce mathematics, plays an essential role on the road to success in this area. In this context, the teacher should select mathematical problems that encourage critical thinking and mathematical reasoning so that the knowledge they receive in school benches resists time.

The difficulty of mathematical problems positions students between challenge and success. Once a math problem is introduced, each student is positioned between challenge and success. The following diagrams show the position of starting and arrival for a particular student at the time he is presented with a problem in math (Figure 2).

Figure 2. Familiarity with (left) and final solution (right) of the problem.
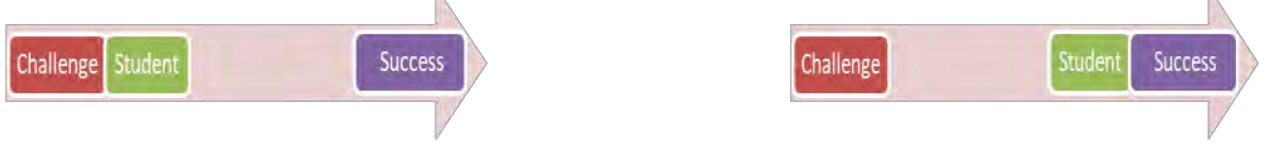

The goal is to shift it to the area of success. This distance is not the same for all students in the class, but the time it takes to achieve success is different for different students.

Despite the distance that challenges and success have for different students, several factors that would narrow this distance and the time to achieve success are:

1) Well-planned design of the teaching techniques. The application of selected techniques and modalities should be accompanied by both parties with perseverance, exchange of ideas and thoughts, specific stimulus questions that excite mathematical reasoning, critical and logical thinking. Students learn to solve problems in mathematics primarily through doing, talking, reflecting, discussing, discussing, observing, investigating, listening, and reasoning (Copley, 2000).

2) Implementation of technology in teaching mathematics, because technology as a cognitive tool does not do the thinking for students, but provide strategies and guidance to help students to process information more efficiently (Drew, Cognitive Tools for Education | 5 Examples, 2020).

3) Creating a supportive climate in the classroom. The classroom should be transformed into an environment that motivates, encourages, supports, and gives opportunities, in an environment where 
everyone, regardless of their abilities, feels like a problem solver in mathematics. The coordination and management of all of the above factors are in the hands of the teacher, because as Sidney Hook puts it, The teacher is the heart of the educational system (SAGE UK, 2020).

\section{Case study}

\subsection{Context}

In the nine-year private school "Imelda Lambertini in Elbasan, Albania there is an annual practice with 6th grade students who start for the first time in Lower Secondary Education (AMU in Albanian).

In the first 3 weeks of teaching with sixth graders, math teaching is somewhat special. These 12 teaching hours are hours of recognition and cooperation that is realized through the solution of problems for each of the main themes assimilated up to the 5 th grade.

This annual practice has multiple purposes, where in addition to consolidating the knowledge gained up to the fifth grade and creating strong foundations to prepare students who are good, problem-solving, math has two important aspects which are in function of further teaching.

First, seen from optimizing pedagogical work as a teacher, this is a period where through research the groups of students are determined according to the learning mode, to plan teaching hours in the function of personalized learning.

Secondly, the identification of new talents in mathematics, to create a group of gifted students with whom to work in a differentiated way.

The choice of learning through problem-solving aims to develop in students the following skills: critical and creative thinking, teamwork, independent and self-directed work, the use of technology, the use of new knowledge in real-life situations.

Equipping the school with a good technological base in recent years has significantly improved math learning outcomes. There has been an increase in the number of students who assimilate for a shorter time the solution of some mathematical problems, as well as the feedback they receive at the moment when different quizzes or questionnaires are treated through the KAHOOT! or other applications!

In one of the hours when the knowledge on the applications of the action of the meeting was being strengthened, the students had to face problematic situation, implemented by authors and presented below.

\subsection{Problem solving process}

Problem situation 1. What is the height of the table? (Figure 3)

Figure 3. Problem 1. What is the height of the table?

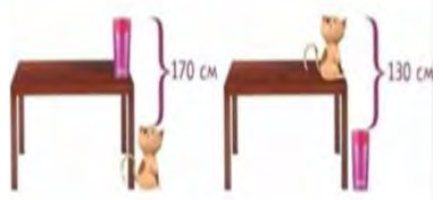

As soon as the problem arose in front of the students, they started asking questions such as: What is the length of the cat, What is the length of the glass, and someone even found that it is a problem with missing data. At first, he was asked to look carefully at the figure, remembering that we were only asked the length of the table, but even after that the situation was turbulent.

The problem has no text for the data, and after it was implemented Polya's First Principle: (Understand the problem) (Polya, 1945) and asking Is there enough information to enable you to find a solution?, the should be 'Yes.'

After the not very clear reactions of the students, the teacher (one of the authors) thought of bringing a very simple problem situation that has been solved in advance, using on the same mathematical concept. We went so far as Polya's Second Principle: Devising the plan: Here is a problem related to you and solved before. Could you use it? (Polya, 1945).

Problem situation 2. For these situations, students needed 2 identical boxes of flour, not filled full, a cup, a glass, a scale. The task was to weigh both boxes in advance and mark the common weight of both boxes together. For the experiment, they were asked to take the first box, remove a cup of flour and add a glass of flour, and weigh it, taking notes of its measure. From the second box students were asked to remove a glass of flour and add a cup of flour, weigh it and mark its weight.

Leading by teacher, they notice that the sum of the measures after these changes is the same as the initial one. $70 \%$ of students explained that this happens because mathematically over the weight of 
$x \mathrm{~kg}$ (which is the mass of the same 2 bags of flour at the beginning), we have added and subtracted the same quantity ( 1 cup of flour and 1 glass of flour), so this mass will remain unchanged.

Dividing by 2 the amount was found: the students found how much the mass of a box with flour in the beginning was. In parallel with the actions performed, the illustrations are made in Smart Board.

The next steps were illustrated on the SmartBoard in the classroom (Figure 4).

Figure 4. Modeling problem situation with SmartBoard.
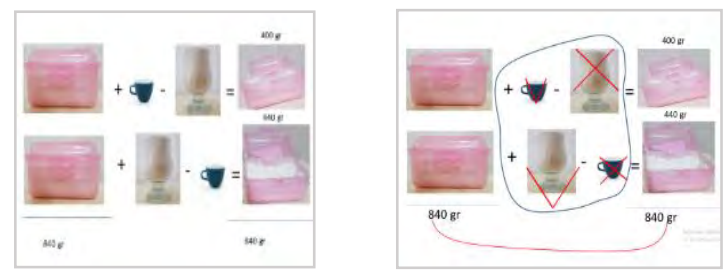

We went back to the case of the problem: After discussion on the analogies of the objects we used in the first problem situation with those of our problem, accurate answers were obtained from most of them.

Students: In the role of the flour box is the length of the table and in the role of the mass of the cup and the glass are the length of the cat and the length of the glass.

By scheming the length of the table, the length of the cat, the length of the glass using rectangles in and after presenting the situation on the SmartBoard, the students understood the solution of the problem, reasoning that: Even in the case of our exercise, the length of the cat and the glass are added and subtracted from both lengths of the same length of the tables. We add together the parts of which we know the total height, in given case $170 \mathrm{~cm}+130 \mathrm{~cm}=300 \mathrm{~cm}$. So the height of the tables is $300 \mathrm{~cm}$. This means that one table is $150 \mathrm{~cm}$ high.

The parts we add are: The white part represents the height missing from the table. This height is the same as the height of the glass in the first figure and the same as the height of the cat in the second (Figure 5).

Figure 5. Scetch of the initial problem on SmartBoard.
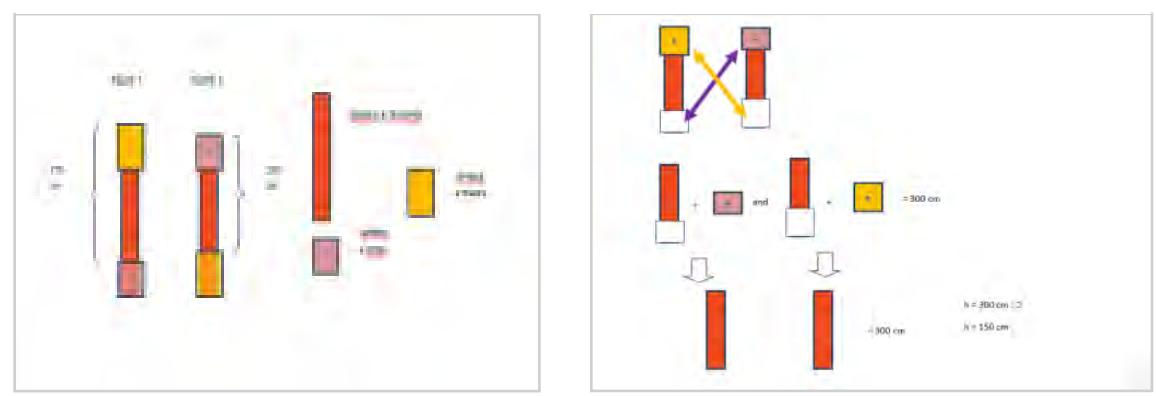

Using the SmartBoard to demonstrate the situation helped students to perceive the solution in their minds because the more senses they use in the learning process, the more productive it becomes.

Problem situation 3. Find the perimeter of the blue figure.

After treating the solution of the previous problem, we moved on to another problem situation which combines elements from the topic of measurement with that of geometry.

Talented students were instantly oriented towards the solution. For the rest of the class, the initial situation was skeptical, as students were looking for another clue.

After taking the right time, the successive instructions for appearing in the SmartBoard of the auxiliary figure, a large part of the students realized that the solution of the exercise was supported by the same theoretical mathematical concept as that of the first problem (Figure 6).

Figure 6. Successive instructions for solving problem.

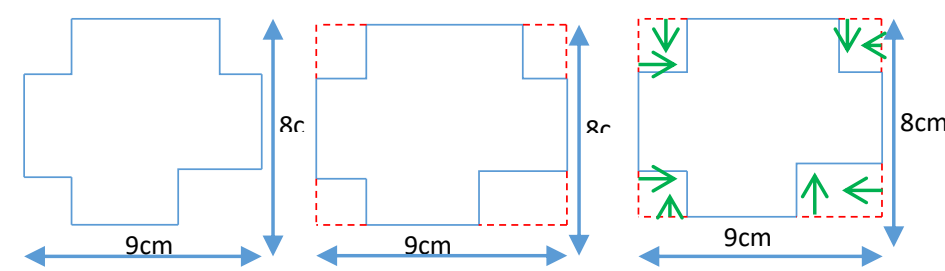


Applying experimental learning, guided practices, accompanied by class discussions and guidelines to conduct research and draw conclusions, strongly supported by ICT produce high-quality teaching hours. Technology develops abstract ideas for teachers by which the student's prior knowledge, abilities, and skills, links to materials with mathematical concepts, address common understandings, and introduce more advanced ideas (Center for Technology in Learning, 2007).

\section{Conclusions}

By applying personalized learning, laying the foundation for problem-learning mathematics, and having strong ICT support, math teachers can ensure students' success in math.

In terms of personalized learning, we can metaphorically say that we can consider students in a class as different flowers in a garden and that they require different ways of caring, while the teacher as a gardener must adopt the service each of the types of flowers in the garden depending on the conditions it requires to grow as qualitatively as possible. In other words, every student should be seen by teacher as unique person and not just as a child.

In terms of problem-solving, applying the principles of problem-solving accompanied by reasoning, experiments and visual presentation of experiments performed, makes it possible to activate many senses in the learning process, thus making it more productive and significantly improves critical thinking and logical reasoning.

The use of ICT (in this case SmartBoard) highlights the activation and interest of students during the lesson, especially those who are visual, auditory, and tactile learners. The results showed the Smart Board's increased interest and activation of students by stimulating them to be the strength of the learning process. On the other hand, it creates happy students, who believe in their abilities and who are activated to achieve success.

But the use of ICT in teaching mathematics, requires good management of the learning process by finding the right technological resources and their use.

\section{Acknowledgments}

The research is partially supported by the Bulgarian Ministry of Education and Science under the National Research Programme "Young scientists and postdoctoral students" approved by DCM \# 577/17.08.2018 and by Sofia University "St. Kliment Ohridski" Research Science Fund project N80-10-199/28.4.2020 "Targeted use of organizational forms embedded in the new MES curriculum in the cultural and educational fields of Mathematics, Informatics and Information Technology"

\section{References}

Bolstad, R., Gilbert, J., McDowall, S., Bull, A., Boyd, S., \& Hipkins, R. (2012). Supporting future-oriented learning and teaching - a New Zealand perspective. Wellington: Ministry of Education, New Zealand.

Center for Technology in Learning. (2007). Why should a teacher use technology in his or her mathematics classroom? SRI International. Retrieved May 22, 2020, from https://education.ti.com/sites/UK/downloads/pdf/Research\%20Notes\%20$\% 20$ Technology\%20in\%20Class.pdf

Copley, J. V. (2000). The young child and mathematics. Washington, DC: National Association for the Education of Young Children.

Couros, G. (2011, Novemer 24). Technology is More than a Tool. Retrieved May 22, 2020, from George Couros Blog: https://georgecouros.ca/blog/archives/2629

Drew, C. (2019). Re-examining cognitive tools: new developments, new perspectives, and new opportunities for educational technology research. Australasian Journal of Educational Technology, 1.

Drew, C. (2020). Cognitive Tools for Education | 5 Examples. Retrieved May 22, 2020, from Helpful Professor: https://helpfulprofessor.com/cognitive-tools/

Leadbeater, C. (2005). The Shape of Things to Come: personalised learning through collaboration. Nottingham: DfES Publications.

National Council of Teachers of Mathematics (NCTM). (2000). Principles and Standards for School Mathematics. Reston, Va: NCTM.

Noor-Ul-Amin, S. (2013). Effective use of ICT for Education and Learning by Drawing on Worldwide Knowledge, Research, and Experience. ICT as a Change Agent for Education, 1-13.

Polya, G. (1945). How to Solve It. Princeton \& Oxford: Princeton University Press.

SAGE UK. (2020). Chapter 1: Looking Forward and Backward at the same time. In Becoming a Teacher. SAGE Publications Inc. 